University of South Carolina

Scholar Commons

$11-2014$

\title{
Biphilic Nanoporous Surfaces Enabled Exceptional Drag Reduction and Capillary Evaporation Enhancement
}

\author{
Xianming Dai \\ University of South Carolina, daix@email.sc.edu \\ Fanghao Yang \\ University of South Carolina, yang74@email.sc.edu \\ Ronggui Yang \\ Xinyu Huang \\ University of South Carolina - Columbia, xyhuang@sc.edu \\ William A. Rigdon
}

See next page for additional authors

Follow this and additional works at: https://scholarcommons.sc.edu/emec_facpub

Part of the Engineering Mechanics Commons, Manufacturing Commons, Materials Science and Engineering Commons, and the Mechanics of Materials Commons

\section{Publication Info}

Published in Applied Physics Letters, Volume 105, Issue 19, 2014, pages 191611-1-191611-5.

(C) Applied Physics Letters, 2014, American Institute of Physics

Dai, X., Yang, F., Yang, R., Huang, X., Rigdon, W., Li, X., Li, C. (2014). Biphilic Nanoporous Surfaces Enabled Exceptional Drag Reduction and Capillary Evaporation Enhancement. Applied Physics Letters, 105(19), 191611-1-191611-5.

http://dx.doi.org/10.1063/1.4901962

This Article is brought to you by the Mechanical Engineering, Department of at Scholar Commons. It has been accepted for inclusion in Faculty Publications by an authorized administrator of Scholar Commons. For more information, please contact digres@mailbox.sc.edu. 


\section{Author(s)}

Xianming Dai, Fanghao Yang, Ronggui Yang, Xinyu Huang, William A. Rigdon, Xiaodong Li, and Chen Li 


\section{Biphilic nanoporous surfaces enabled exceptional drag reduction and capillary evaporation enhancement}

Xianming Dai', Fanghao Yang, Ronggui Yang, Xinyu Huang, William A. Rigdon, Xiaodong Li, and Chen Li'

Citation: Appl. Phys. Lett. 105, 191611 (2014); doi: 10.1063/1.4901962

View online: http://dx.doi.org/10.1063/1.4901962

View Table of Contents: http://aip.scitation.org/toc/apl/105/19

Published by the American Institute of Physics

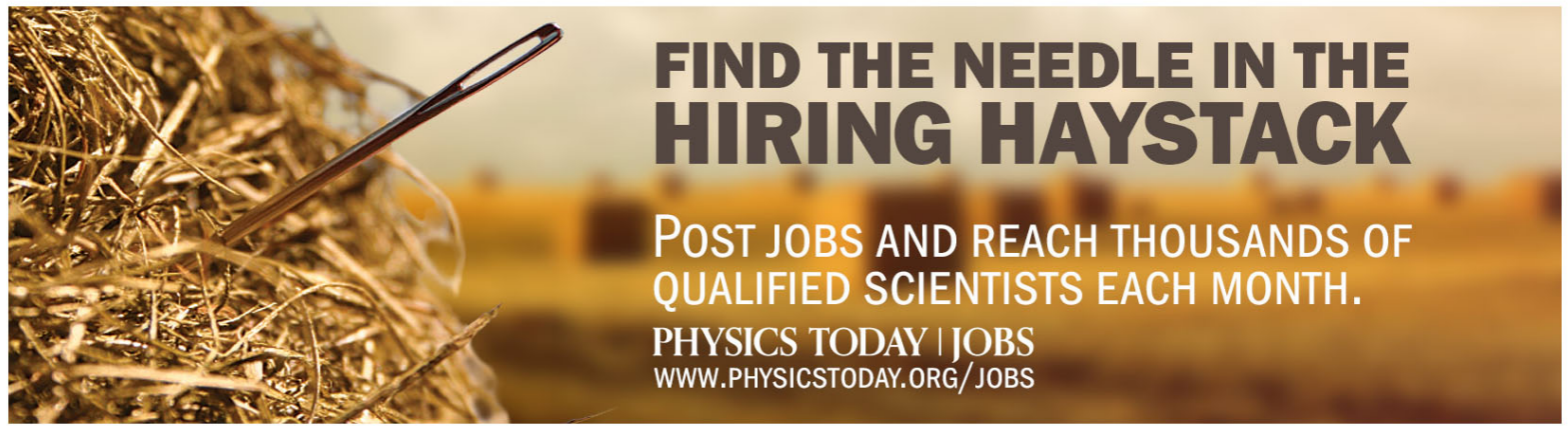




\title{
Biphilic nanoporous surfaces enabled exceptional drag reduction and capillary evaporation enhancement
}

\author{
Xianming Dai, ${ }^{1, a)}$ Fanghao Yang, ${ }^{1}$ Ronggui Yang, ${ }^{2}$ Xinyu Huang, ${ }^{1}$ William A. Rigdon, ${ }^{1}$ \\ Xiaodong $\mathrm{Li}^{3}$ and Chen $\left.\mathrm{Li}^{1, \mathrm{~b}}\right)$ \\ ${ }^{1}$ Department of Mechanical Engineering, University of South Carolina, Columbia, South Carolina 29208, USA \\ ${ }^{2}$ Department of Mechanical Engineering, University of Colorado, Boulder, Colorado 80309, USA \\ ${ }^{3}$ Department of Mechanical and Aerospace Engineering, University of Virginia, Charlottesville, Virginia \\ 22904, USA
}

(Received 25 September 2014; accepted 5 November 2014; published online 14 November 2014)

\begin{abstract}
Simultaneously achieving drag reduction and capillary evaporation enhancement is highly desired but challenging because of the trade-off between two distinct hydrophobic and hydrophilic wettabilities. Here, we report a strategy to synthesize nanoscale biphilic surfaces to endow exceptional drag reduction through creating a unique slip boundary condition and fast capillary wetting by inducing nanoscopic hydrophilic areas. The biphilic nanoporous surfaces are synthesized by decorating hydrophilic functional groups on hydrophobic pristine multiwalled carbon nanotubes. We demonstrate that the carbon nanotube-enabled biphilic nanoporous surfaces lead to a $63.1 \%$ reduction of the friction coefficient, a $61.7 \%$ wetting speed improvement, and up to $158.6 \%$ enhancement of capillary evaporation heat transfer coefficient. A peak evaporation heat transfer coefficient of $21.2 \mathrm{~W} /\left(\mathrm{cm}^{2} \cdot \mathrm{K}\right)$ is achieved on the biphilic surfaces in a vertical direction. (C) 2014 AIP Publishing LLC.
\end{abstract}

[http://dx.doi.org/10.1063/1.4901962]

Solid-liquid interfacial characteristics such as interfacial wettability, surface roughness, and the presence of micro/nano bubbles govern fluid flow and heat transfer. Hydrophobic surfaces can reduce friction owing to the interfacial slippage, ${ }^{1-3}$ while nanotextured superhydrophobic surfaces inevitably trap gas as a lubricant in nanopores, resulting in a significant drag reduction owing to the shear-free boundary conditions between the liquid and gas. ${ }^{4}$ However, hydrophobic surfaces exhibit poor capillarity since they cannot form concave menisci. ${ }^{5}$ On the other hand, nucleate boiling can be enhanced using hydrophobic surfaces via augmenting nucleation site density. The small pinning forces of vapor bubbles on hydrophobic surfaces can substantially increase the bubble departure frequency. ${ }^{6}$ Nonetheless, an earlier transition from nucleate boiling to film boiling on hydrophobic surfaces results in low critical heat fluxes (CHFs). ${ }^{7}$ For example, carbon nanotubes (CNTs) can reduce friction, ${ }^{8}$ enhance boiling, ${ }^{9-14}$ and evaporation, ${ }^{15,16}$ but enhancements are limited by their intrinsic hydrophobicity, which prohibits the generation of favorable capillarity.

Hydrophilic surfaces, which contain a large amount of concave menisci with small radii, are superior to generating capillary forces to improve liquid spreading ${ }^{3}$ during boiling/ evaporation heat transfer processes. Superhydrophilic surfaces can promote nucleate boiling and thin film evaporation through augmenting the wetting areas. ${ }^{17,18}$ However, hydrophilic surfaces can induce higher flow resistance because of the induced non-slip boundary conditions owing to the complete wetting characteristics when compared to hydrophobic ones. Additionally, bubble departure on the hydrophilic

\footnotetext{
${ }^{a)}$ Current address: Department of Mechanical and Nuclear Engineering, Pennsylvania State University, University Park, PA 16802, USA.

b) Author to whom correspondence should be addressed. Electronic mail: Li01@mailbox.sc.edu
}

surfaces can be retarded by the high pinning forces on the contact line and the nucleation cavities suffer from flooding. ${ }^{19}$

To achieve superior fluid flow and heat transfer rate during nucleate boiling and evaporation, hybrid surfaces consisting of both hydrophilic and hydrophobic features are highly desirable because the composite surface wettability is superior to liquid spreading by generating favorable capillarity and maintaining low friction. ${ }^{20,21}$ Although these composite surfaces with microscale hydrophilic and hydrophobic areas have been developed to enhance capillary flow ${ }^{22,23}$ and boiling heat transfer, ${ }^{22,24}$ they can neither impact the nanoscopic slip length nor effectively reduce the pinning forces governed by the contact line. ${ }^{25}$ CNT-enabled hydrophobichydrophilic nanoporous surfaces have been shown to substantially enhance nucleate boiling in our previous study by tuning surface wettability at nanoscale. ${ }^{19}$ However, a systematic exploration of drag reduction and capillary evaporation enhancement on such a type of biphilic nanoporous surfaces is still lacking.

In this study, the biphilic nanoporous surfaces, which are synthesized by creating hydrophilic functional groups on the hydrophobic pristine CNTs in the defected areas, are used to reduce flow friction and to enhance capillary evaporation. Such functionalized multiwalled CNTs (FMWCNTs) developed in this work exhibit the advantages of both hydrophobic and hydrophilic characteristics. Commercialized 8-15 nmO.D. multiwalled CNTs (MWCNTs, Cheaptubes Inc., Cambridgeport, Virginia, USA) (Fig. 1(a)) were oxidized in concentrated nitric acid to grow carboxyl and hydroxyl functional groups on the defect areas (i.e., vacancies). ${ }^{19}$ Then, the biphilic CNTs were dispersed in the isopropyl alcohol with the aid of high power ultrasonic horn disruption. Amphiphilic Nafion was added to primarily improve the dispersion as a surfactant and strengthen the bonding between functionalized MWCNT (FMWCNT) wires and the substrate. ${ }^{3}$ The locations 


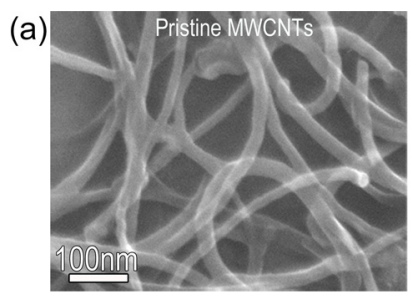

(b)
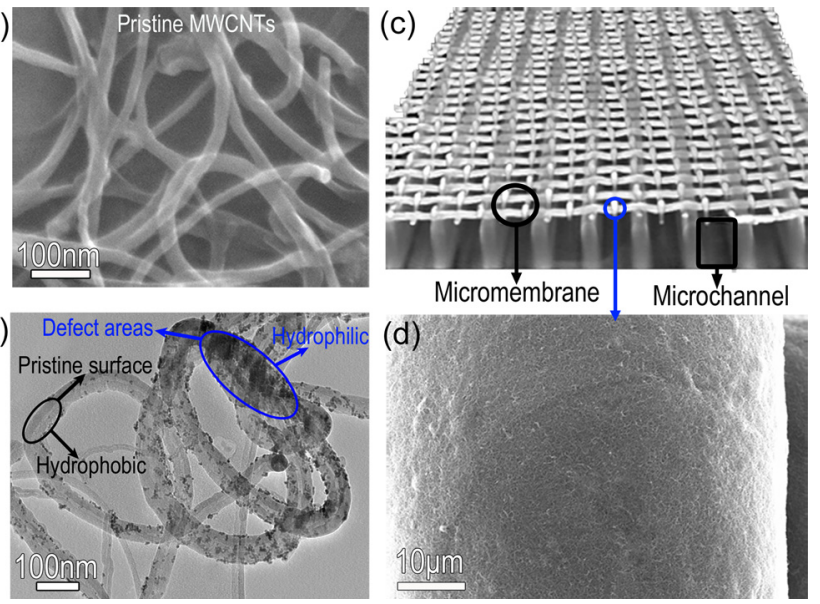

FIG. 1. Characteristics of the biphilic nanoporous coated MEMs. (a) Hydrophobic pristine MWCNTs. (b) The biphilic nanoporous with both hydrophobic and hydrophilic wetting features where hydrophilic functional groups are grown on hydrophobic pristine CNTs. (c) Micro-XCT (x-ray computed tomography) image of MEMs. (d) The biphilic nanoporous coatings on the copper wire surface.

of the functional groups on the biphilic MWCNT wires and bundles can be traced using positive charged platinum ions (Fig. 1(b)). ${ }^{3}$ Platinum nano-particles loaded on defect areas where functional groups grow indirectly indicate the distribution of hydrophilic areas. ${ }^{26}$

Drag reduction and capillary evaporation are experimentally studied in a single microchannel and membraneenhanced microchannels (MEMs), respectively. ${ }^{3}$ The flow resistance is studied in a single microchannel (Height, width, and length: $0.15 \mathrm{~mm}, 5.5 \mathrm{~mm}$, and $26 \mathrm{~mm}$ ) with the biphilic nanoporous coatings on the bottom surface (Fig. 2(a)). The pressure drop, $\Delta p$, in the microchannel, which is defined as $\Delta p=p_{\text {in }}-p_{\text {out }}$, is measured using a differential pressure transducer $\left(\right.$ Omega $\left.{ }^{\circledR}\right)$, where $p_{\text {in }}$ and $p_{\text {out }}$ are the inlet and outlet pressures (Fig. 2(a)). ${ }^{3}$ Friction coefficient in the bare and biphilic nanoporous microchannels are 0.31 and 0.19 at a Reynolds number of 200, respectively, yielding a $63.1 \%$ reduction of the friction coefficient (Fig. 2(b)). The biphilic nanoporous surfaces can trap nanobubbles inside hydrophobic pores and result in a significant drag reduction owing to the nanoscale gas-liquid slip boundary. ${ }^{27}$

Wetting speed and capillary evaporation are experimentally studied in MEMs. The MEMs is fabricated by diffusionbonding a single-layer $1509 \mathrm{~m}^{-1}$ copper woven meshes with a wire diameter of $56 \mu \mathrm{m}$ (Belleville Wire Cloth Co., Inc.) on a straight microchannel array (Height, width, and length:
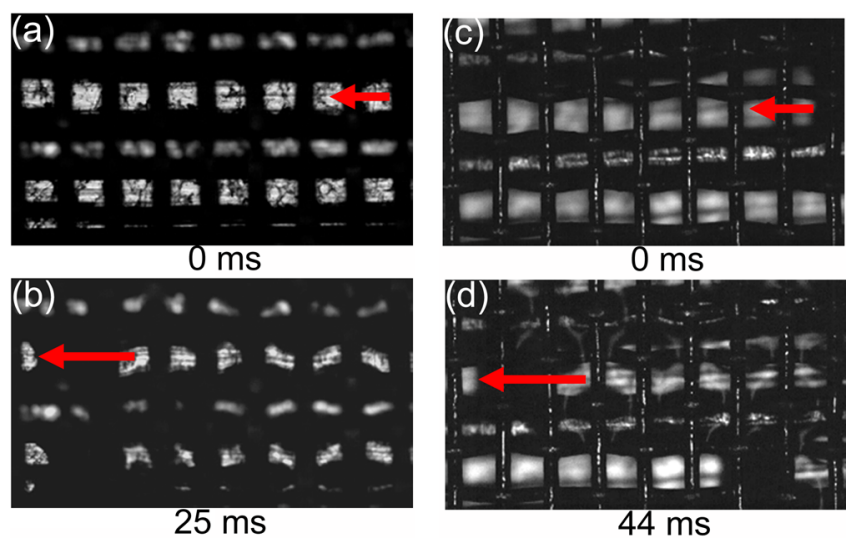

$0 \mathrm{~ms}$

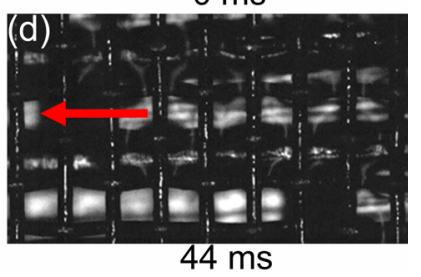

FIG. 3. Capillary wetting in MEMs with and without the biphilic nanoporous coatings. (a) and (b) Wetting speed in the biphilic nanoporous coated copper MEMs. (c) and (d) Wetting speed in the bare copper MEMs.

$0.25 \mathrm{~mm}, 0.25 \mathrm{~mm}$, and $20 \mathrm{~mm}$ ) (Fig. 1(c)). ${ }^{28}$ The wick and heating areas are $1 \mathrm{~cm}^{2}$. During the evaporation test, the biphilic MEMs are positioned in the vertical direction with the center of the heating block $15 \mathrm{~mm}$ away from water level. ${ }^{3}$ The well-dispersed mixtures of amphiphilic Nafion and biphilic MWCNTs were deposited on MEMs by an ultrasonic spray coater, yielding MEMs with hierarchical porosity and biphilicity.

The wetting speeds of water in the horizontal MEMs without and with the biphilic nanoporous surfaces are measured by a high speed camera linked to a microscope. The wetting speeds is significantly increased to $26.2 \mathrm{~cm} / \mathrm{s}$ in the biphilic coated MEMs (Figs. 3(a)-3(d)) from $16.2 \mathrm{~cm} / \mathrm{s}$ in the bare copper MEMs (Movies 1 and 2), ${ }^{3}$ accounting for a $61.7 \%$ higher liquid spreading speed. Unlike the non-wettable CNT-coated MEMs, the biphilic coatings can still be wetted and generate a large capillary force to spread liquid, resulting in a rapid capillarity-enhanced wetting phenomenon. In short, we demonstrate that the biphilic nanoporous surfaces can significantly reduce friction (Fig. 2(b)) by inducing slip boundary conditions. Moreover, they can maintain great capillarityenhanced liquid spreading (Figs. 3(a)-3(d)).

To examine the effect of the unique wettability of the biphilic nanoporous surfaces on phase-change heat transfer, capillary evaporation on the MEMs with three different types of coatings (i.e., superhydrophilic $\mathrm{ALD} \mathrm{SiO}_{2}$, hydrophobic MWCNTs, and biphilic nanoporous coatings) is experimentally studied. The effects of wettability on evaporation are evaluated and comprehensively compared to understand enhancement mechanisms. The apparent contact angles are (a)

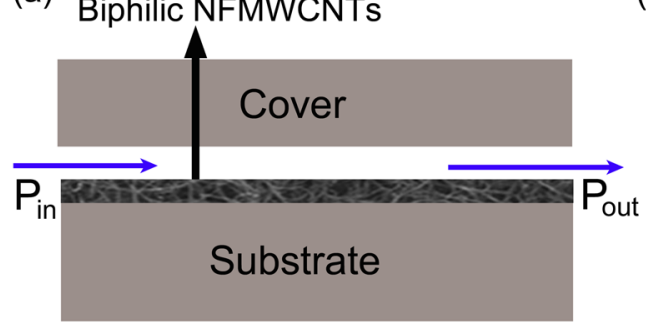

Fluid flow through microchannel

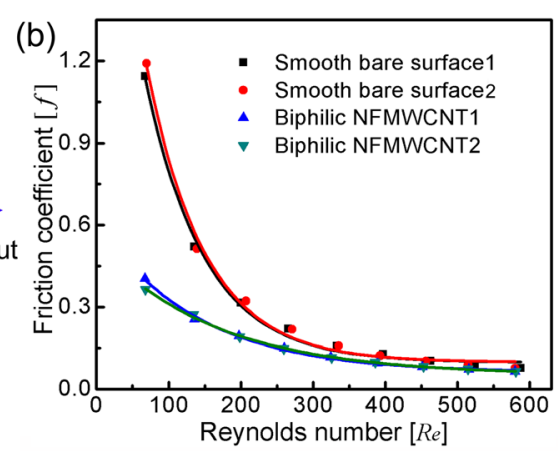

FIG. 2. Characterization of drag reduction on the biphilic nanoporous surfaces in a single microchannel. (a) Pressure driven flow through the microchannel with partially wetting surfaces, $\mathrm{P}_{\text {in }}$-inlet pressure, and $\mathrm{P}_{\text {out }}$-outlet pressure (supplementary material). ${ }^{3}$ (b) Flow resistance measurement through the single microchannel with the biphilic coatings. 
measured (Fig. 4(a)). According to the liquid distribution and flow characteristics on the bare MEMs, the capillary evaporation in MEMs can be divided into three regions (Figs. 4(b) and 4(c)). ${ }^{21}$ Region I $\left(0-11.2 \mathrm{~W} / \mathrm{cm}^{2}\right)$ is dominated by nucleate boiling and oscillating flows; region II $\left(11.2-57.2 \mathrm{~W} / \mathrm{cm}^{2}\right)$ is governed by static wetting and thin film evaporation; and region III $\left(57.2-152.2 \mathrm{~W} / \mathrm{cm}^{2}\right)$ is determined by nucleate boiling, capillary wetting, and thin film evaporation.

Compared to the bare MEMs, all three types of coatings aforementioned can enhance the heat transfer coefficient (HTC) significantly (Fig. 4(b)). Though the degree of enhancements varies in all three regions, the biphilic nanoporous surfaces overall outperform other types of coatings. In region $\mathrm{I}$, HTCs of $7.0 \mathrm{~W} /\left(\mathrm{cm}^{2} \cdot \mathrm{K}\right)$ on the bare MEMs, $8.8 \mathrm{~W} /\left(\mathrm{cm}^{2} \cdot \mathrm{K}\right)$ on the intrinsically superhydrophilic ALD $\mathrm{SiO}_{2}$, and $18.1 \mathrm{~W} /\left(\mathrm{cm}^{2} \cdot \mathrm{K}\right)$ on the biphilic nanoporous coatings are achieved at a heat flux of $28.9 \mathrm{~W} / \mathrm{cm}^{2}$, indicating $105.6 \%$ and $158.6 \%$ enhancements compared to the ALD-coated $\mathrm{SiO}_{2}$ and bare ones. In region II, thin film evaporation dominates heat transfer after fluid oscillations are suspended. The deteriorated liquid supply results in partial dryout on these surfaces with spatially uniform wettability, lowering HTCs. However, the biphilic nanoporous coatings can still maintain great wetting conditions (Figs. 4(c) and 4(e)) and a higher HTC of $9.8 \mathrm{~W} /\left(\mathrm{cm}^{2} \cdot \mathrm{K}\right)$ compared to the $5.8 \mathrm{~W} /\left(\mathrm{cm}^{2} \cdot \mathrm{K}\right)$ obtained on the bare one at a heat flux of $57.1 \mathrm{~W} / \mathrm{cm}^{2}$ owing to the superior liquid spreading enabled by the hybrid wettability.

Enhancement mechanisms of capillary evaporation are more complicated in region III. In the high heat flux region,
HTC rises from $7.5 \mathrm{~W} /\left(\mathrm{cm}^{2} \cdot \mathrm{K}\right)$ on the bare MEMs to $10.5 \mathrm{~W} /\left(\mathrm{cm}^{2} \cdot \mathrm{K}\right)$ on the pristine CNT coatings at a heat flux of $104.3 \mathrm{~W} / \mathrm{cm}^{2}$. The maximum HTC on $\mathrm{ALD} \mathrm{SiO}_{2}$ coatings is $14.2 \mathrm{~W} /\left(\mathrm{cm}^{2} \cdot \mathrm{K}\right)$ at a heat flux of $151.7 \mathrm{~W} / \mathrm{cm}^{2}$, which reflects an increase of $61.4 \%$ compared to the bare MEMs. The maximum HTC of $13.5 \mathrm{~W} /\left(\mathrm{cm}^{2} \cdot \mathrm{K}\right)$ on the $80 \mathrm{~nm}$-thick biphilic nanoporous coating is achieved at a heat flux of $168.7 \mathrm{~W} / \mathrm{cm}^{2}$ (Fig. 4(b)), which is an increase of $53.4 \%$ over the bare MEMs because of the enhanced thin film evaporation resulting from the the superhydrophilic $\mathrm{ALD} \mathrm{SiO}_{2}$ coatings. ${ }^{17}$ The intrinsically hydrophobic MWCNTs augmented the nucleation site density and surface areas, yielding enhanced nucleate boiling and thin film evaporation. Not surprisingly, the poor wettability substantially reduced $\mathrm{CHF}$. Apparently, more nucleation sites can be activated with increasing superheat according to the nucleate boiling theory on the biphilic nanoporous coatings and lead to higher HTC. $^{6}$ We also compared our results with an evaporation study on biporous wicks with similar sample size and working conditions (i.e., $1 \mathrm{~cm}^{2}$ heating area and $1.5 \mathrm{~cm}^{2}$ wick area in vertical direction with $10 \mathrm{~mm}$ away from the water level to the center of heating area). ${ }^{20}$ In the high heat flux region, the peak HTC of the present $80 \mathrm{~nm}$ biphilic MEMs is $13.4 \mathrm{~W} /\left(\mathrm{cm}^{2} \cdot \mathrm{K}\right)$, resulting in $22.9 \%$ higher than $10.9 \mathrm{~W} /\left(\mathrm{cm}^{2} \cdot \mathrm{K}\right)$ based on the heating area, which is $50 \%$ smaller than the wick area.

The thickness effect of the biphilic nonporous coatings on HTCs was experimentally studied since it affects nucleation site densities, surface areas, and fluid spreading. Figures 4(d) and 4(e) show the thickness effect in a range of the coating thickness from $80 \mathrm{~nm}$ to $1600 \mathrm{~nm}$ (Figs. 4(d) and 4(e)). (a)
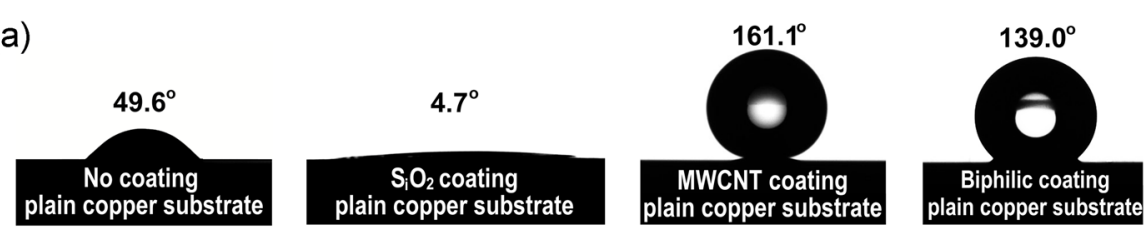
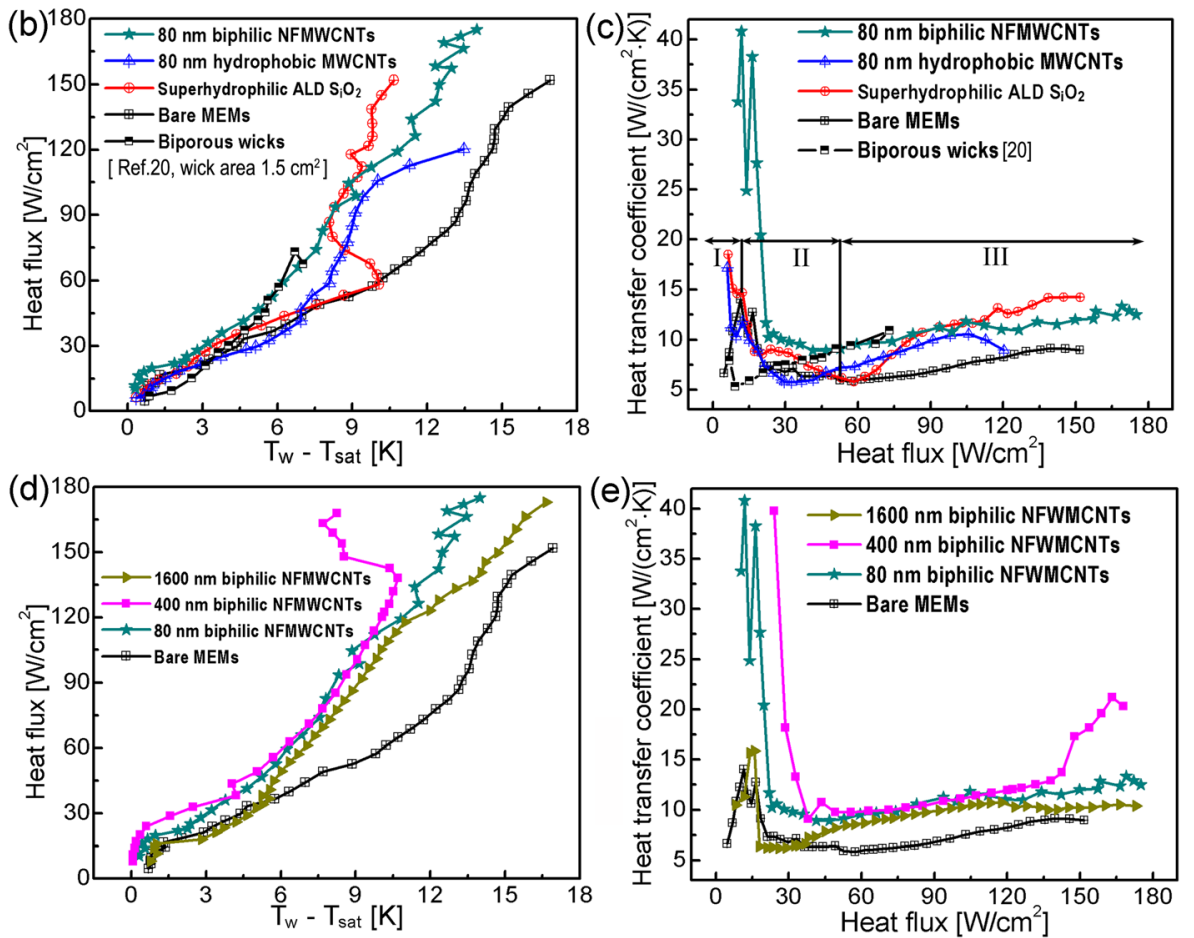

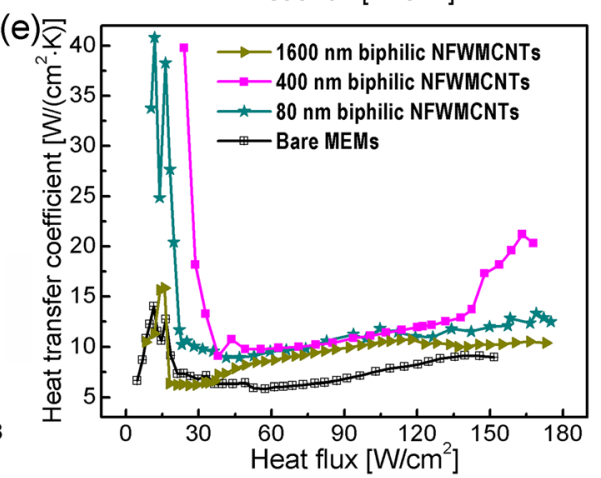

FIG. 4. Capillary evaporation on the biphilic nanoporous MEMs. (a) Surface wettability of plain copper surfaces on various types of coatings. (b) Capillary evaporation curves. (c) Heat flux-heat transfer coefficient (HTC) curves. (d) Thickness effect of the biphilic nanoporous coatings on capillary evaporation. (e) Thickness effect of the biphilic nanoporous coatings on the HTC. 

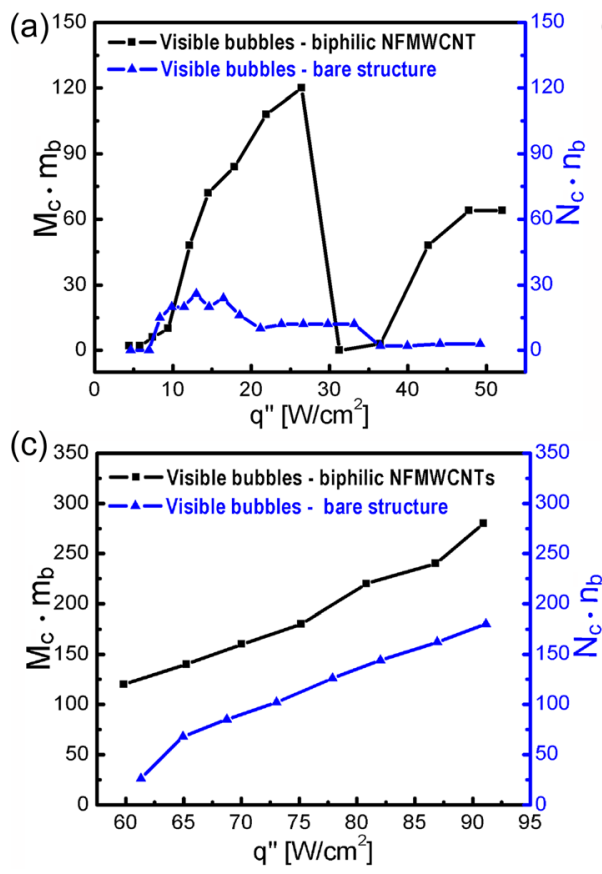
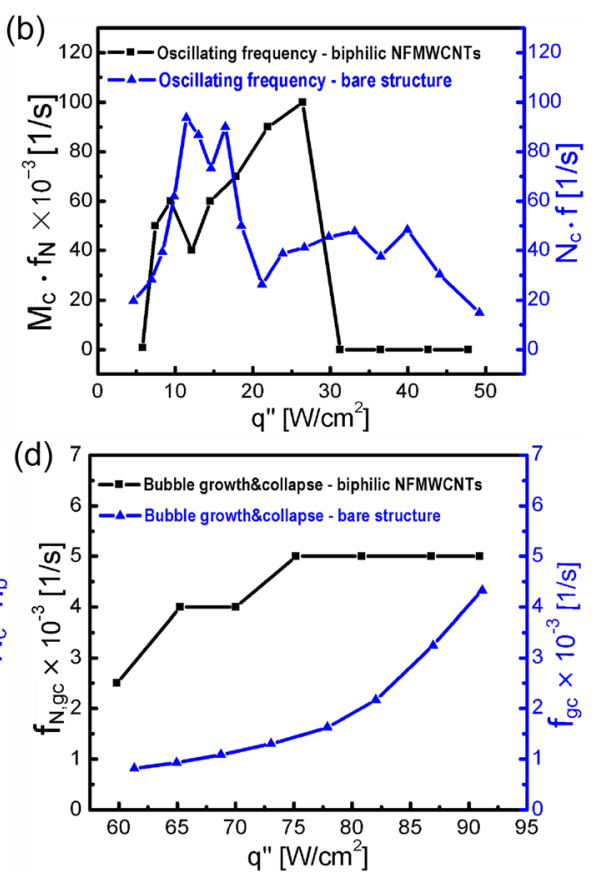

FIG. 5. Mechanism of enhanced capillary evaporation on the biphilic MEMs. (a) The total number of visible bubbles in active channels with the biphilic nanoporous coatings, $M_{c} \cdot m_{b} \cdot M_{c}$ is the number of visible bubbles in a single active channel, and $m_{b}$ is the number of active channels. $\mathrm{N}_{\mathrm{c}} \cdot \mathrm{n}_{\mathrm{b}}$ is for bare MEMs. (b) The total oscillating frequency, $\mathrm{M}_{\mathrm{c}} \cdot \mathrm{f}_{\mathrm{N}}$, in the biphilic MEMs; $\mathbf{M}_{\mathrm{c}}$ is the number of active channels, and $f_{N}$ is the frequency of fluid flow in a single active channel. $\mathrm{N}_{\mathrm{c}} \cdot \mathrm{f}$ is for bare MEMs. (c) The total number of visible bubbles in active channels, $\mathrm{M}_{\mathrm{c}} \cdot \mathrm{m}_{\mathrm{b}}$ in the high heat flux region. $\mathrm{N}_{\mathrm{c}} \cdot \mathrm{n}_{\mathrm{b}}$ is for bare MEMs. (d) Bubble growth and collapse frequency, $f_{N, g c} \cdot f_{g c}$ is for bare MEMs.
The conformal superhydrophilic ALD $\mathrm{SiO}_{2}$ coatings can enhance wetting conditions and thin film evaporation as demonstrated in our earlier work. ${ }^{17}$ Even though the $80 \mathrm{~nm}$ thick biphilic nanoporous surface provide more nucleate cavities than the conformal ALD coatings, it still underperforms ALD $\mathrm{SiO}_{2}$ coatings due to the additional thermal resistance (Figs. 4(c) and 4(e)). For the $400 \mathrm{~nm}$-thick coatings, a significantly larger amount of cavities would be activated in the biphilic nanoporous coatings compared to $\mathrm{ALD} \mathrm{SiO}_{2}$ coatings. The HTC dramatically increases with the heat flux higher than $142.8 \mathrm{~W} / \mathrm{cm}^{2}$ because of a higher nucleation site density. ${ }^{6}$ The overall maximum HTC of $21.2 \mathrm{~W} /\left(\mathrm{cm}^{2} \cdot \mathrm{K}\right)$ is achieved at a heat flux of $163.1 \mathrm{~W} / \mathrm{cm}^{2}$ on the $400 \mathrm{~nm}$-thick biphilic nonporous coatings, an increase of $133.0 \%$ over the bare MEMs (Fig. 4(e)) and $94.5 \%$ over the biporous wick. ${ }^{20}$ However, HTC downturn shows up with the further increase of coating thickness. For example, $1600 \mathrm{~nm}$-thick biphilic nanoporous coatings even underperform $80 \mathrm{~nm}$-thick coatings (Figs. 4(c) and 4(e)). Specifically, when the heat flux is less than $118.3 \mathrm{~W} / \mathrm{cm}^{2}$, liquid supply is abundant even on $1600 \mathrm{~nm}$-thick coatings, yielding an enhanced HTC due to the augmented nucleation site densities. But when the heat flux is higher than $118.3 \mathrm{~W} / \mathrm{cm}^{2}$, HTC starts to decrease until approaching $\mathrm{CHF}$ conditions. It appears that the thermal resistance is getting higher because the non-wetted porous layer becomes thicker, which cannot be overcome by the enhanced nucleate boiling and evaporation that only occur in the wetted areas. This indicates that an optimal coating thickness to maximize HTC exists.

To further investigate the HTC enhancement mechanisms, visualizations of capillary flow and bubble dynamics on the bare, superhydrophilic $\mathrm{ALD} \mathrm{SiO}_{2}$, and biphilic nanoporous coated MEMs are conducted. Enhanced wetting conditions are maintained on both the superhydrophilic ALD $\mathrm{SiO}_{2}$ and biphilic nanoporous coated MEMs, ${ }^{3}$ but the biphilic nanoporous coatings can form a large amount of partially wetting cavities, which can enhance nucleate boiling. ${ }^{3}$ As experimentally validated, the superheat on the biphilic nanoporous coatings is substantially reduced to $0.6^{\circ} \mathrm{C}$ (Fig. 4(b)). In addition, the biphilic nanoporous surfaces dramatically increase the oscillating flows and advection (Movies 3 and 4$)^{3}$ owing to the sustainable wettability, which considerably enhances the liquid spreading and therefore HTC. Visualization study shows that both nucleate boiling (Fig. 5(a)) and oscillating frequency (Fig. 5(b)) are substantially increased. Figures 5(c) and 5(d) also illustrate that the both nucleation site density and bubble growth-collapse frequency increase after applying the biphilic nonporous coatings (Movies 3 and 4), ${ }^{3}$ which confirms that the HTC enhancement on the biphilic nanoporous surfaces primarily results from enhanced nucleate boiling, advection, and thin film evaporation in region III.

Surface wettability affects CHF of capillary evaporation. CHF drops from $151.7 \mathrm{~W} / \mathrm{cm}^{2}$ on the bare MEMs to $120.3 \mathrm{~W} / \mathrm{cm}^{2}$ on the pristine CNT coated surfaces (Figs. 4(b)) due to the reduced capillarity. Superhydrophilic ALD $\mathrm{SiO}_{2}$ coatings are also incapable of improving CHF because the enhanced capillary force is balanced by the increased flow friction as shown in our previous study. ${ }^{17}$ However, the biphilic nonporous coatings can increase CHF to $171.7 \mathrm{~W} /$ $\mathrm{cm}^{2}$ from $151.7 \mathrm{~W} / \mathrm{cm}^{2}$ on the bare MEMs (Fig. 4(b)). Compared to the biporous wicks, ${ }^{20}$ the CHF on the biphilic nanoporous coatings is $141.7 \%$ higher. The biphilic nonporous coatings can enhance the overall liquid supply and delay CHF conditions in two aspects: hydrophobic areas can effectively reduce the flow resistance while hydrophilic functional groups induce capillarity-enhanced liquid spreading. In addition, during the evaporation heat transfer process, the biphilic nanoporous surfaces can reduce the size of vapor bubble and increase the bubble growth and collapse frequency (Movie 3), ${ }^{3}$ which intensifies fluid oscillations and hence improving liquid supply and $\mathrm{CHF}$.

In summary, the biphilic nanoporous coatings enabled by the FMWCNTs are demonstrated to enhance both heat and mass transport. The flow drag is considerably reduced 
through the slip boundary conditions induced by trapping gas lubricants. Liquid spreading is improved owing to the reduced friction and the generation of capillary forces. The partially wetting nanoporous coated MEMs exhibited enhanced capillary evaporation performances in both HTC and CHF. The increased HTC primarily results from the improved wetting areas, intensified oscillating fluid flow, and augmented nucleate boiling; while the improved $\mathrm{CHF}$ primarily benefits from the drag reduction and increased bubble growth-collapse frequency.

This work was supported by the startup funds of University of South Carolina (USC) to Dr. Li and Dr. Huang and Office of Naval Research under Grant Nos. N000140810080 and N000141210724 to Dr. Li. The authors thank USC Electron Microscopy Center for instrument use, scientific and technical assistance. Yingchao Yang's help on the scratch test is also greatly appreciated.

${ }^{1}$ C. Neto, D. R. Evans, E. Bonaccurso, H. J. Butt, and V. S. J. Craig, Rep. Prog. Phys. 68(12), 2859 (2005).

${ }^{2}$ C. Cottin-Bizonne, B. Cross, A. Steinberger, and E. Charlaix, Phys. Rev. Lett. 94(5), 056102 (2005).

${ }^{3}$ See supplemenrtary material at http://dx.doi.org/10.1063/1.4901962 for FMWCNT synthesis and coating, sintering methods, drag reduction, capillary evaporation, visualization studies, and movies.

${ }^{4}$ P. Tsai, A. M. Peters, C. Pirat, M. Wessling, R. G. H. Lammertink, and D. Lohse, Phys. Fluids. 21(11), 112002 (2009).

${ }^{5}$ E. Dujardin, T. W. Ebbesen, H. Hiura, and K. Tanigaki, Science 265(5180), 1850 (1994).

${ }^{6}$ Y. Y. Hsu, J. Heat Transfer: Trans. ASME 84, 207 (1962).

${ }^{7}$ N. A. Patankar, Soft Matter 6(8), 1613 (2010).
${ }^{8}$ K. K. S. Lau, J. Bico, K. B. K. Teo, M. Chhowalla, G. A. J. Amaratunga, W. I. Milne, G. H. McKinley, and K. K. Gleason, Nano Lett. 3(12), 1701 (2003).

${ }^{9}$ S. Ujereh, T. Fisher, and I. Mudawar, Int. J. Heat Mass Tranfer 50(19-20), 4023 (2007).

${ }^{10}$ V. Sathyamurthi, H. S. Ahn, D. Banerjee, and S. C. Lau, J. Heat Transfer: Trans. ASME 131(7), 071501 (2009).

${ }^{11}$ K.-J. Park and D. Jung, Int. J. Heat Mass Transfer 50(21-22), 4499 (2007).

${ }^{12}$ V. Khanikar, I. Mudawar, and T. Fisher, Int. J. Heat Mass Tranfer 52(15-16), 3805 (2009).

${ }^{13}$ N. Singh, V. Sathyamurthy, W. Peterson, J. Arendt, and D. Banerjee, Int. J. Heat Fluid. Flow 31(2), 201 (2010).

${ }^{14}$ J. P. McHale, S. V. Garimella, T. S. Fisher, and G. A. Powell, Nanosc. Microsc. Thermophys. Eng. 15(3), 133 (2011).

${ }^{15}$ Q. Cai and C.-L. Chen, J. Heat Transfer: Trans. ASME 132(5), 052403 (2010).

${ }^{16}$ E. Terrado, R. Molina, E. Natividad, M. Castro, P. Erra, D. Mishkinis, A. Torres, and M. T. Martinez, J. Phys. Chem. C 115(19), 9312 (2011).

${ }^{17}$ X. M. Dai, M. Famouri, A. I. Abdulagatov, R. G. Yang, Y. C. Lee, S. M. George, and C. Li, Appl. Phys. Lett. 103(15), 151602 (2013).

${ }^{18}$ J. L. Plawsky, A. G. Fedorov, S. V. Garimella, H. B. Ma, S. C. Maroo, L. Chen, and Y. Nam, Nanosc. Microsc. Thermophys. Eng. 18(3), 251 (2014).

${ }^{19}$ X. M. Dai, X. Y. Huang, F. H. Yang, X. D. Li, J. Sightler, Y. C. Yang, and C. Li, Appl. Phys. Lett. 102(16), 161605 (2013).

${ }^{20}$ D. Coso, V. Srinivasan, M.-C. Lu, J.-Y. Chang, and A. Majumdar, J. Heat Transfer: Trans. ASME 134(10), 101501 (2012).

${ }^{21}$ X. M. Dai, F. H. Yang, R. G. Yang, Y. C. Lee, and C. Li, Int. J. Heat Mass Tranfer 64, 1101 (2013).

${ }^{22}$ S. Daniel, M. K. Chaudhury, and J. C. Chen, Science 291(5504), 633 (2001).

${ }^{23}$ D. T. Wasan, A. D. Nikolov, and H. Brenner, Science 291(5504), 605 (2001).

${ }^{24}$ A. R. Betz, J. Xu, H. Qiu, and D. Attinger, Appl. Phys. Lett. 97(14), 141909 (2010).

${ }^{25}$ A. T. Paxson and K. K. Varanasi, Nat. Commun. 4, 1492 (2013).

${ }^{26}$ J.-P. Tessonnier, A. Villa, O. Majoulet, D. S. Su, and R. Schlögl, Angew. Chem. Int. Ed. 48(35), 6543 (2009).

${ }^{27}$ C. Cottin-Bizonne, J.-L. Barrat, L. Bocquet, and E. Charlaix, Nat. Mater. 2(4), 237 (2003).

${ }^{28}$ M. Eroglu, T. I. Khan, and N. Orhan, Mater. Sci. Technol. 18(1), 68 (2002). 